\title{
TITLE: The UK vs Sweden: Is the NHS Really So Bad?
}

STANDFIRST: An international comparison of cardiovascular patient mortality between the

UK and Sweden does not provide convincing evidence that faster uptake of primary PCI or beta-blockers on discharge would have had an effect on cardiovascular patient mortality in the UK.

\section{Introduction}

The primary goal of collecting data and auditing care against standards is to improve the quality of care, and thereby, to improve patient outcomes. One important outcome, though not the only one, is mortality. This is the focus of the painstaking work of Sheng-Chia Chung and colleagues reported in The Lancet ${ }^{1}$ on 23 January 2014 and reproduced in summary form in the BMJ. ${ }^{\underline{2}}$ They suggest that "more than 10000 deaths at 30 days would have been prevented or delayed had UK patients experienced the care of their Swedish counterparts." Further, they estimate that 1741 deaths would have been prevented in the UK had the Swedish pattern of primary percutaneous coronary intervention (PCI) and beta-blocker use been replicated in the NHS from 2004 to 2010. Do their analyses support these conclusions?

\section{Confirmation of Transnational Difference}

The Health Statistics 2013 database ${ }^{3}$ provides data on 30-day mortality from AMI, including hospital and community deaths, for the United Kingdom calculated from Hospital Episode Statistics (HES), and for Sweden calculated from the Swedish National Patient Register [Figure 1]. The rate for the United Kingdom in 2008 was $12 \cdot 0 \%$, compared to $9 \cdot 7 \%$ for Sweden (relative ratio: $1 \cdot 24$ ). The gap has been narrowing. By 2011 that relative ratio of 30-day mortality had fallen to 1·17.

Figure 1: Trends in acute myocardial infarction (ICD10-I21, I22) patient-based 30-day (in-hospital and out of hospital) mortality from 2000 to 2011 for patients 45 years and over, adjusted for age and sex (rate per 100 patients) ${ }^{3}$

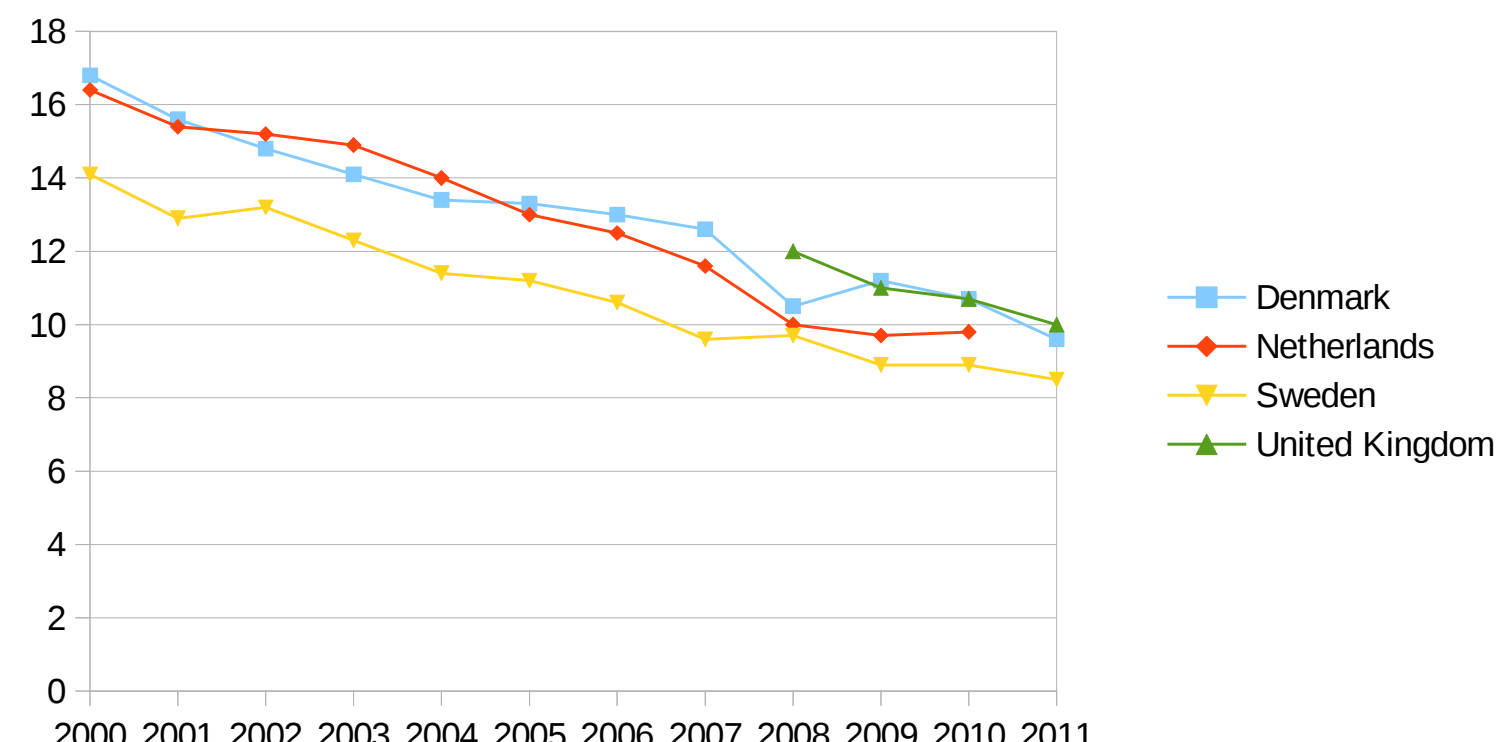


These numbers broadly coincide with the findings of Chung and colleagues even though their more detailed data came from sources with lower apparent rates of case ascertainment. ${ }^{4, \underline{5}}$ They estimated 30-day mortality (2004 through 2010) in the UK at $10 \cdot 5 \%$ and $7 \cdot 6 \%$ in Sweden, and a casemixstandardised mortality ratio of $1 \cdot 37$ (CI: $1 \cdot 30-1 \cdot 45)$. Thus the Lancet report provides one more

5 confirmation of previously reported ${ }^{\underline{6}}$ transnational differences in 30-day mortality for acute myocardial infarction (AMI).

How much of this important difference in outcome - a difference that was persistent but diminishing as mortality rates fell in both countries and elsewhere across Europe - can reasonably be attributed to deficiencies and inefficiencies in care provided by the National Health Service? How much of that gap from 2004 through 2010 could be said to be due to "far quicker"7 uptake and use in Sweden of new technologies and effective treatments recommended in guidelines, especially primary PCI in ST-segment-elevation myocardial infarction (STEMI) and beta-blockers on discharge?

\section{The Apparent Mortality Gap and the Uptake of New Treatments}

Notwithstanding explicit caveats, largely ignored by mainstream media, ${ }^{\mathrm{Z}, \underline{8}}$ Chung and colleagues suggest that "more than 10000 deaths at 30 days would have been prevented or delayed had UK patients experienced the care of their Swedish counterparts.” Further, they estimate that 1741 deaths would have been prevented in the UK had the Swedish pattern of primary PCI and beta-blocker use been replicated in the NHS from 2004 to 2010.

We believe that the authors have overstated their case.

As noted in the accompanying commentary in The Lancet,, 9 the analysis that the authors undertook to estimate the potential number of deaths prevented by Swedish-style primary PCI and beta-blocker use assumed that the size of benefits seen in randomised controlled trials translated into real-world patients. Yet they found only a slight hint of a downwards shift in the standardised mortality ratio, from 1.37 to 1.31 when the different provision of these two interventions was taken into account. However, neither the authors of the original paper, nor the authors of the commentary, consider that the confidence interval for the second estimate $(1 \cdot 30-1 \cdot 33)$ is contained entirely within the confidence interval for the first $(1 \cdot 30-1 \cdot 45)$. The logical conclusion is that there is no identifiable change at all, so, while clearly showing higher rates of primary PCI and prescription of

35 beta-blockers in Sweden, the study actually provides no evidence for the proposition that there were excess deaths at 30 days due to slower adoption of new technology (primary PCI) in the United Kingdom.

Moreover, when we consider that the addition of in-hospital treatment variables (including time from the onset of symptoms to intervention) to the 17-variable casemix adjustment in the authors' simulation study did not fully explain the 30-day mortality gap between Sweden and the United Kingdom - the estimate decreased from $1 \cdot 37$ to $1 \cdot 21$ (CI: $1 \cdot 15-1 \cdot 29)$ - we cannot reasonably surmise anything more than that an unknown set of factors which may even be exogenous to cardiovascular care are responsible for the evident differences in mortality between the two

45 countries. The fact that the reported confidence intervals around the estimates are just barely disjoint, the dependence of the simulations on clinical trial effect sizes, and the lack of sufficient detail around those simulations to enable their replication, encourages us to be especially cautious in accepting and interpreting these results. 
Perhaps the relevant factors are unmeasured aspects of cardiovascular care such as whether patients are admitted to hospital under the care of a cardiologist, or the quality of PCI performance in nSTEMI patients. Perhaps they are factors that are endemic to the population - for example, cultural differences in the response to heart attack or genetic make-up - but it is equally possible that they are entirely illusory. For patients under 80 years of age in 2012, case ascertainment for Swedish hospitals ranges from $56 \%$ to $95 \% .{ }^{5}$ For hospital admissions for myocardial infarction overall in the UK, case ascertainment may range from $64 \%{ }^{4}$ to $75 \% .{ }^{10}$ We cannot broadly discount the possibility that the unexplainable difference in 30-day mortality between the United Kingdom and Sweden is due to fundamental differences in case ascertainment rates, data collection practices, and other analytically-important but clinically-irrelevant considerations.

In support of this hypothesis we also considered OECD and World Health Organisation data obtained from death registries of member states, putatively understood to be reporting the medically-certified cause-of-death, to look at overall age- and sex-adjusted mortality attributed to acute myocardial infarction [Figure 2]. How can the steady relative worsening of the Swedish AMI mortality experience be reconciled with their faster uptake of primary PCI and other treatment modalities? This phenomenon illustrates an Achilles heel of international comparative epidemiology: one rarely knows if one is really comparing like to like.

\section{Figure 2: Trends in overall acute myocardial infarction mortality from 1979 to 2010 for patients 45 years and over, adjusted for age and sex (deaths per 100000 population) ${ }^{3}$}

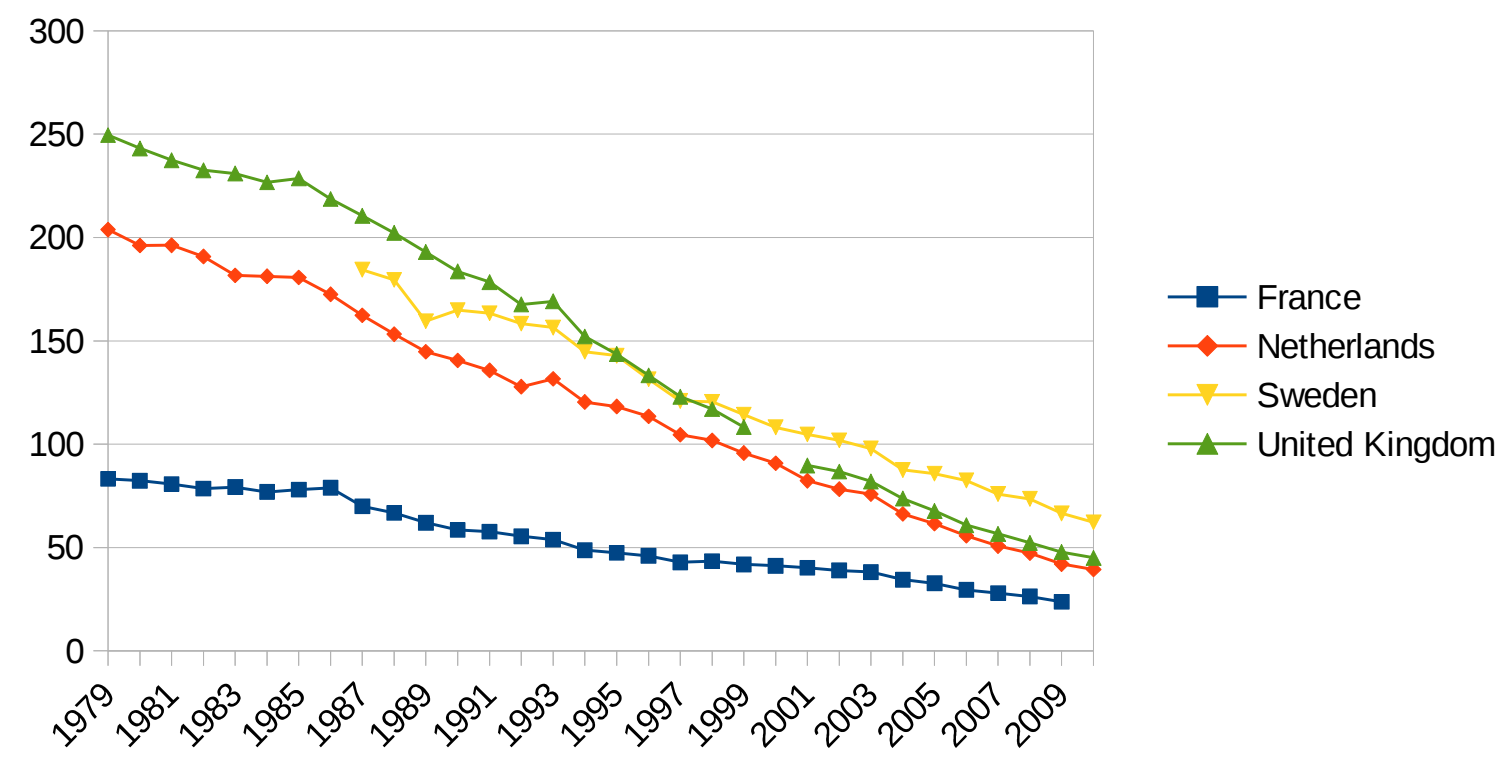

We conclude that the headline of "more than 10000 deaths at 30 days would have been prevented or delayed", which in the lay press became "more than 11,000 lives could have been saved"

25 "thousands of heart attack patients have died unnecessarily due to 'second-rate care"”- is misleading. At most, the study by Chung and colleagues tells us that there may have been up to 9000 apparent excess myocardial infarction deaths at 30 days in the United Kingdom relative to Sweden that could not be attributed to the provision or otherwise of those evidence-based cardiovascular care interventions that were measured.

Even if the NHS may be slower to adopt some new health technologies relative to certain other national health services, there are good reasons why a slower and more methodical approach may 
often be necessary. These include evaluation of effectiveness and adverse events in the population at large, and a need for meticulous and thorough training of new users during the technology roll-out. There is no convincing evidence in the analyses presented in The Lancet paper that a faster uptake of primary PCI or beta-blockers on discharge would have had any effect on cardiovascular patient mortality.

\section{KEY MESSAGES:}

- An international comparison of cardiovascular patient mortality between the UK and Sweden does not provide convincing evidence that more than 11000 lives would have been
saved over seven years if the NHS had provided the same care to patients in the UK as was
provided to patients in Sweden.

- The uptake of new treatments should continue to be methodical, not rushed, to ensure their effectiveness and to reduce the chances of adverse effects resulting from their adoption.

\section{REFERENCES:}

1 Chung SC, Gedeborg R, Nicholas O, et al. Acute myocardial infarction: a comparison of short-term survival in national outcome registries in Sweden and the UK. The Lancet 2013; doi:10.1016/S0140-6736(13)62070-X.

2 Wise J. Lower myocardial infarction survival in UK than Sweden blamed on slow uptake of new treatments. BMJ 2014;348:g426.

3 Figures based on data from OECD Health Data 2013. http://www.oecd.org/health/healthsystems/oecdhealthdata.htm, accessed on 23 January 2014.

4 Herrett, E, Shah AD, Boggon, R, et al. Completeness and diagnostic validity of recording acute myocardial infarction events in primary care, hospital care, disease registry, and national mortality records: cohort study. BMJ 2013;346:f2350.

$5 \quad$ Annual Report SWEDEHEART 2012: RIKS-HIA Annual report 2012. Downloaded from

30 http://www.ucr.uu.se/swedeheart/index.php/arsrapporter/doc download/254-swedeheart-annual-rep ort-2012-english .

$6 \quad$ Appleby J. Does poor health justify NHS reform? BMJ 2011; 342:d566.

$7 \quad$ BBC News, Health. UK heart-attack survival rate 'should have been better'. Accessed at http://www.bbc.co.uk/news/health-25841930 .

$358 \quad$ Sky News. 'Second-rate care' for heart attack patients. Accessed at http://news.sky.com/story/1199483/second-rate-care-for-heart-attack-patients .

9 Gale CP, Fox KAA. International comparisons of acute myocardial infarction. The Lancet 2013; doi:10.1016/S0140-6736(13)62367-3.

10 Gavalova L, Weston C, Birkhead J, et al. Myocardial Ischaemia National Audit Project

40 (MINAP): How the NHS cares for patients with heart attack. Tenth Public Report 2011. Accessed at http://www.ucl.ac.uk/nicor/audits/minap/publicreports/pdfs/minappublicreport2011 .

\section{Acknowledgements:}

45 OECD is the source and copyright owner of the data presented in Figures 1 and 2, and in the accompanying discussion. 